\title{
Developing a Family of Curves for the HEC-18 Scour Equation
}

\author{
Timothy Calappi ${ }^{1}$, Carol Miller ${ }^{1}$, Donald Carpenter ${ }^{2}$, Travis Dahl ${ }^{3}$ \\ ${ }^{1}$ Department of Civil and Environmental Engineering, Wayne State University, \\ Detroit, USA \\ ${ }^{2}$ Department of Civil Engineering, Lawrence Technological University, \\ Southfield, USA \\ ${ }^{3}$ United States Army Corps of Engineers, Detroit, USA \\ Email: tcalappi@wayne.edu,cmiller@eng.wayne.edu,dcarpente@ltu.edu,travis.dahl@usace.army.mil
}

Received October 21, 2011; revised January 20, 2012; accepted February 25, 2012

\begin{abstract}
Accurate pier scour predictions are essential to the safe and efficient design of bridge crossings. Current practice uses empirical formulas largely derived from laboratory experiments to predict local scour depth around single-bridge piers. The resulting formulas are hindered by insufficient consideration of scaling effects and hydrodynamic forces. When applied to full-scale designs, these formula deficiencies lead to excessive over prediction of scour depths and increased construction costs. In an effort to improve the predictive capabilities of the HEC-18 scour model, this work uses field-scale data and nonlinear regression to develop a family of equations optimized for various non-cohesive soil conditions. Improving the predictive capabilities of well-accepted equations saves scarce project dollars without sacrificing safety. To help improve acceptance of modified equations, this work strives to maintain the familiar form of the HEC18 equation. When compared to the HEC-18 local pier scour equation, this process reduced the mean square error of a validation data set while maintaining over prediction.
\end{abstract}

Keywords: Scour; Piers; Bridges; Erosion; Estimation; Failures; Bridge Foundations

\section{Introduction}

Riverbed scour is a continuous process with natural and anthropomorphic causes. Local accelerations in river velocity increase the ability for a river to erode sediment. Bridge support structures at river crossings create local acceleration. Removing enough sediment from the river bottom near bridge piers or abutments can cause the bridge to become unstable, increasing the risk of failure.

According to the Federal Highway Administration, the United States has approximately 600,000 bridges; about 80 percent require some sort of scour mitigation [1]. Due to uncertainty in current scour prediction equations, ultimate scour depth is typically overestimated to ensure safety. While the incremental cost for deeper foundations may be reasonable for a small bridge with a single pier, it can be exorbitant for larger bridges with several largediameter piers. Decreasing uncertainty associated with scour-prediction models can lead to cheaper construction costs without sacrificing safety.

Over the last few decades, statistical and physical modeling dominated scour research with the goal of relating hydrodynamics, geometry and sediment data to scour depth. Empirically derived scour prediction equations, largely based on experimental flume data using cohesionless sediment, currently dominate the state of the practice. Although laboratory data are the most typical source of data to define relationships affecting pier scour [2], it does not capture the complexity of bridge scour due to difficulties in scaling effects $[3,4]$. Scaled physical models often use sediment of similar size as the field condition they represent. Sediment is difficult to scale due to cohesive effects and the presence of bed forms are determined by particle size relative to the height of the viscous sublayer [4]. Uncertainty also stems from the fact that the ranges of the various parameters over which the equations are valid are typically unknown [5]. Considerable uncertainty is also associated with these equations due to difficulties in measuring complex velocity fields and bathymetry in the field.

The Federal Highway Administration issued Hydraulic Engineering Circular (HEC) 18 [6], HEC-20 [7] and HEC23 [8] to provide guidance for local scour determinations. HEC-18 provides specific guidance regarding the prediction of local pier scour depth primarily through the empirically derived Equation (1) [6]: 


$$
\frac{y_{s}}{y_{1}}=2.0 K_{1} K_{2} K_{3} K_{4}\left(\frac{a}{y_{1}}\right)^{0.65} F r^{0.43}
$$

where $y_{s}$ is the scour depth, $a$ is the pier width, $K_{1}$ is the correction factor for pier nose shape, $K_{2}$ is the correction factor for the angle of attack (the angle at which the flow impinges upon the pier, $K_{3}$ is the correction factor for bed condition (plane bed, dune, ripple), $K_{4}$ is the correction factor for armoring by bed material size, $y_{1}$ is the flow depth directly upstream of the pier and Fr is the Froude number. The remainder of this work refers to $\left(a / y_{1}\right)$ as the normalized pier width (NPW). Equation (1) represents the state of the practice and is included in one-dimensional hydraulic models such as the Hydraulic Engineering Center-River Analysis System [9]. Equation (1) is based on work performed at Colorado State University and is frequently referred to as the CSU equation.

Attempts to improve fit and reduce uncertainty in commonly used scour prediction equations appeared in the 1990s when researchers, such as [5] tried using field data to determine valid ranges for typical parameters. Johnson [5] also compared several competing models based on computed bias in predictions. Johnson concluded some equations were not fit for design purposes because they often under predict scour. Conversely, equations used for design purposes over predict with a large, positive bias leading to an improved design from a safety perspective, while unnecessarily increasing construction costs [5].

For this effort, the National Bridge Scour Database (NBSD) provided field-scale data for an attempt to improve the scour prediction capabilities of the HEC-18 local pier scour equation. The NBSD, last updated in 2004 and maintained by the US Geologic Survey (USGS), provides data from 20 sites in eight states [10]. For selection, a record must contain enough data to apply the current version of the HEC-18 scour equation.

\section{Methods}

No single equation reliably predicts scour in all scenarios, Ettema et al. [11]. The goal of the present effort is to reduce mean square error of scour prediction through the development and application of a family of scour prediction equations. Each member of the family is similar in form to HEC-18, but with various exponents applied to the normalized pier width and Froude number. Currently, these exponents are fixed in HEC-18 and apply for all conditions. Maintaining the form of HEC-18 as the basis for the non-linear regression ensures previously identified parameters important in describing the scour process are included. That is, no attempt is made to link important scour parameters to a new functional form. Grouping similar data and splitting the domain into multiple regions provides a mechanism to develop multiple equations termed a family of equations. Each member is tailored to specific conditions.

Generally, the proposed model will require development of several pairs of exponents, each pair developed for a specific set of conditions. Collectively, the equations generated from each exponent pair, apply to the same broad range of conditions as the current HEC-18 equation. Specifically, this effort will develop two pairs of exponents (Case 1 and Case 2) applicable to live-bed scour where the median particle size is in the sand fraction, Equation (2). The value of the normalized pier width, as defined by the geometry and flow conditions at the study site, delineates the choice of exponent pairs for Case 1 and Case 2. Case 1 is defined as live-bed scour, median particle size in the sand fraction and a normalized pier width less than 0.3. Case 2 is defined the same as Case 1 but the normalized pier width ranges from 0.3 to 1.25 . Figure 1 illustrates the decision process used to choose exponents for the current work as well as exponents for future development.

$$
\frac{y_{s}}{y_{1}}=K\left(\frac{a}{y_{1}}\right)^{b_{1}} F^{b_{2}}
$$

The parameters in Equation (2) are defined the same as in Equation (1) where $K$ is the collection of $K_{1}$ through $K_{4}$ and $b_{1}$ and $b_{2}$ are regression coefficients to be determined.

\subsection{Data Description}

The National Bridge Scour Database contains 148 records meeting all of the conditions described above (complete for HEC-18 application, cohesionless, live-bed scour and $\mathrm{D}_{50}<2 \mathrm{~mm}$ ). These records represent 20 unique sites from eight states (Alaska, Colorado, Georgia, Indiana, Louisiana, Missouri, Mississippi and Ohio). Due to limited representation in the database, eleven records with a normalized pier width greater than or equal to 1.25 were removed. Table 1 provides descriptive statistics

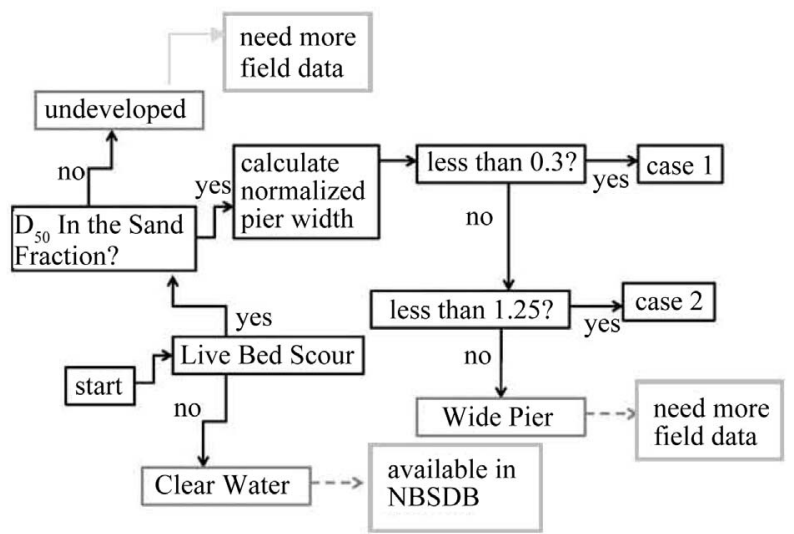

Figure 1. Flow chart depicting currently derived equations and conditions where equations still need to be derived. 
Table 1. Combined descriptive statistics for Case 1 and Case 2 data.

\begin{tabular}{cccccc}
\hline Variable & Mean & Median & $\begin{array}{c}\text { Standard } \\
\text { Deviation }\end{array}$ & Min & Max \\
\hline $\begin{array}{c}\text { Normalized } \\
\text { pier width }\end{array}$ & 0.35 & 0.29 & 0.22 & 0.043 & 1.18 \\
$\begin{array}{c}\text { Froude } \\
\text { Median grain } \\
\text { size (mm) }\end{array}$ & 0.25 & 0.24 & 0.12 & 0.04 & 0.55 \\
\hline
\end{tabular}

from the remaining queried data.

This analysis requires two datasets from the queried records: one set to derive and validate exponents for Case 1 (described above), and the other dataset to derive and validate exponents for Case 2. The median normalized pier width was determined and the values used to split the 137 records into two datasets. From Table 1, the median normalized pier width is 0.29 and rounded to 0.3 for this analysis. Currently, HEC-18 uses a special correction factor for wide piers (i.e. normalized pier widths greater than 1.25). This criterion provides a natural upper bound for the normalized pier widths for Case 2. Analyses for Case 1 and Case 2 were performed with 71 and 66 records, respectively. Data for each analysis is described in

\section{Table 2.}

Multiple visits to the same bridge or multiple piers from a single bridge generate multiple records in the database. The datasets used in Case 1 and Case 2 model development were further parsed into derivation and validation datasets. However, records from a single site were prevented from simultaneously contributing to both the derivation and validation datasets. This prevented sitespecific processes from artificially increasing performance statistics on the validation dataset. For example, if a specific location contributes five records to a dataset and that site is chosen to contribute to the derivation dataset, then all five records will be in the derivation dataset.

The process of splitting the data into derivation and validation data was repeated four times. Each time, the site, or combination of sites contributing records to the validation dataset changed. Resampling continued until each site contributed to both the derivation and validation datasets. This technique ensured the equations developed with this process did not rely on the records chosen to be in the derivation and validation datasets.

\subsection{Regression Types}

The HEC-18 pier scour equation was re-derived with nonlinear regression analysis which will both under-and over predicts scour. Therefore, an adjustment factor is applied to the best-fit equation to minimize the number of under predictions. Two adjustment factors were considered in this study, a multiplicative adjustment as in the current HEC-18 equation and an additive adjustment as
Table 2. Descriptive statistics for national bridge scour database data.

\begin{tabular}{lccccc}
\hline \multicolumn{6}{c}{ National Bridge Scour Database-Froude } \\
\hline & Mean & Std. Dev & Min & Max & $\begin{array}{c}\text { Number of } \\
\text { Records }\end{array}$ \\
\hline Case 1 & 0.18 & 0.09 & 0.04 & 0.37 & 71 \\
Case 2 & 0.32 & 0.10 & 0.16 & 0.55 & 66 \\
\multicolumn{6}{c}{ National Bridge Scour Database—- $D_{50}(\mathrm{~mm})$} \\
Case 1 & 0.74 & 0.33 & 0.16 & 1.82 & 71 \\
Case 2 & 0.89 & 0.54 & 0.15 & 1.80 & 66 \\
\hline
\end{tabular}

in the Froehlich Design Equation [12]. Equations (3a) and ( $3 \mathrm{~b}$ ) provide the two forms of the adjusted equations examined in this study.

$$
\begin{aligned}
& \frac{y_{s}}{y_{1}}=K\left(\frac{a}{y_{1}}\right)^{b_{1}} F r^{b_{2}} * \text { adjustment } \\
& \frac{y_{s}}{y_{1}}=K\left(\frac{a}{y_{1}}\right)^{b_{1}} F r^{b_{2}}+\text { adjustment }
\end{aligned}
$$

The adjustment factors are computed by examining the maximum under-prediction of scour from the deriving data set. The multiplier required to increase the most under-predicted value in the deriving data set to the observed value was determined. Relative scour depth ratios in the validation data set were predicted using the best-fit equation and increased by the multiplicative adjustment. Similarly, the additive adjustment was determined and added to each best-fit prediction in the validation set.

This study applied four different regression techniques to Equation (2) and investigated the ability of Equations (3a) and (3b) (for both Case 1 and Case 2) to over predict observed scour but by a lesser margin than the current HEC-18 local pier scour equation. Regression techniques include:

- Unrestricted, ordinary least-squares;

- Unrestricted, weighted least-squares;

- Restricted, ordinary least-squares;

- Restricted, weighted least-squares.

The National Bridge Scour Database includes information describing the accuracy for each scour measurement. Accuracy ranged from \pm 0.08 meters to \pm 0.61 meters. The weighted regression schemes considered the measurement accuracy for each record to determine the regression parameters. For example, records with high accuracy had more influence in the fitting process than inaccurately measured records. Each record in the ordinary regression models were considered equally precise and assigned equal weight. Restricted regression helped maintain intuitive ranges on regression parameters.

\section{Results}

This process results in a series of equations based on 
various regression forms and types. The mean-square error and number of over predictions were determined for each case and for each resampling. Not all regression types or forms resulted in over-predicted scour depths or a reduced mean square error compared to the original HEC-18 equation. However, the restricted, ordinary, leastsquares (OLS) regression applied to Equation (3b) consistently over-predicted scour depth (at least as often as the current HEC-18 model), but with a smaller mean square error than the current HEC-18 implementation. Table 3 summarizes the mean square error and number of over predictions from each of the resampled validation data sets. The remainder of this manuscript focuses on comparing OLS Equation (3b) and the current HEC-18 local pier scour equation.

In every sampling for Case 1 and Case 2 records, the modified version over predicted scour as often as the current HEC-18 approach (Table 4). The mean square error for each sample was also determined for both Case 1 and Case 2. Mean square errors for the original HEC18 ranged from 0.06 to 1.55 and from 0.01 to 0.38 for the modified version and were generally higher for Case 2 in both the original and modified models (Table 5).

In order to maximize the number of records used in equation development, all available data was used to derive a final pair of equations but only after a regression type (restricted OLS) and model form (Equation (3b)) were determined through the four re-sampled trials. The first case with $a / y_{1}<0.3$ is predicted with Equation (4a) and Case 2 with $0.3 \leq a / y_{1}<1.25$ predicted by Equation (4b). The 95-percent confidence interval around the regression parameters for each trial are shown in Table 6. The exponents of the final equations fit within the bounds of the exponents based on the four resampled cases.

Table 3. Average MSE and number of over predictions from resampled validation data sets.

\begin{tabular}{ccccccc}
\hline & \multicolumn{3}{c}{ NPW $<0.30$} & \multicolumn{3}{c}{$0.30 \leq \mathrm{NPW}<1.25$} \\
\hline & Original & Modified & P-value & Original & Modified P-Value \\
\hline MSE & 0.23 & 0.03 & 0.0001 & 1.05 & 0.30 & 0.001 \\
$\begin{array}{c}\text { Over } \\
\text { Prediction }\end{array}$ & $70 / 71$ & $70 / 71$ & & $65 / 66$ & $65 / 66$ & \\
\hline
\end{tabular}

Table 4. Number of over predictions for original and modified models.

\begin{tabular}{ccccccc}
\hline $\begin{array}{c}\text { Over } \\
\text { Predictions } \\
\text { trials 1 to 4 }\end{array}$ & \multicolumn{2}{c}{$\begin{array}{c}\text { Original } \\
\text { HEC-18 }\end{array}$} & \multicolumn{2}{c}{$\begin{array}{c}\text { Multiplicative } \\
\text { Adjustment }\end{array}$} & \multicolumn{2}{c}{$\begin{array}{c}\text { Additive } \\
\text { Adjustment }\end{array}$} \\
\hline & Case 1 & Case 2 & Case 1 & Case 2 & Case 1 & Case 2 \\
\hline Trial 1 & 17 & 19 & 14 & 19 & 17 & 18 \\
Trial 2 & 19 & 15 & 18 & 15 & 19 & 15 \\
Trial 3 & 17 & 13 & 17 & 10 & 17 & 14 \\
Trial 4 & 17 & 18 & 10 & 16 & 17 & 18 \\
\hline
\end{tabular}

Table 5. Mean square error for trials 1 to 4 from models developed with restricted, ordinary least-squares regression for both Case one and Case two.

\begin{tabular}{ccccccc}
\hline $\begin{array}{c}\text { Over } \\
\text { Predictions } \\
\text { Trials 1 to 4 }\end{array}$ & $\begin{array}{c}\text { Original } \\
\text { HEC-18 }\end{array}$ & \multicolumn{2}{c}{$\begin{array}{c}\text { Multiplicative } \\
\text { Adjustment }\end{array}$} & \multicolumn{2}{c}{$\begin{array}{c}\text { Additive } \\
\text { Adjustment }\end{array}$} \\
\hline & Case 1 & Case 2 & Case 1 & Case 2 & Case 1 & Case 2 \\
\hline Trial 1 & 0.46 & 1.55 & 0.18 & 7.26 & 0.02 & 0.14 \\
Trial 2 & 0.15 & 1.09 & 0.09 & 0.50 & 0.04 & 0.39 \\
Trial 3 & 0.25 & 0.96 & 0.36 & 1.04 & 0.03 & 0.39 \\
Trial 4 & 0.06 & 0.14 & 0.03 & 0.04 & 0.01 & 0.29 \\
\hline
\end{tabular}

Table 6. Modified exponents $b_{1}$ and $b_{2}$ with corresponding $\mathbf{9 5 \%}$ confidence limits for each trial.

\begin{tabular}{|c|c|c|c|c|c|c|}
\hline \multirow[t]{2}{*}{$\begin{array}{l}\text { Regression } \\
\text { Coefficients } \\
\text { Case } 1\end{array}$} & \multicolumn{2}{|c|}{$\begin{array}{l}\text { Case } 1 \\
\text { Lower }\end{array}$} & \multicolumn{2}{|c|}{$\begin{array}{l}\text { Case } 1 \\
\text { Best Fit }\end{array}$} & \multicolumn{2}{|c|}{$\begin{array}{l}\text { Case } 1 \\
\text { Upper }\end{array}$} \\
\hline & $b_{1}$ & $b_{2}$ & $b_{1}$ & $b_{2}$ & $b_{1}$ & $b_{2}$ \\
\hline Trial 1 & 1.13 & -0.55 & 1.86 & 0 & 2.59 & 0.55 \\
\hline Trial 2 & 1.27 & -0.40 & 1.72 & 0 & 2.18 & 0.40 \\
\hline Trial 3 & 0.69 & 0.03 & 1.22 & 0.5 & 1.75 & 1.03 \\
\hline Trial 4 & 1.37 & 0.39 & 1.81 & 0 & 2.26 & 0.39 \\
\hline \multirow[t]{2}{*}{$\begin{array}{l}\text { Regression } \\
\text { Coefficients } \\
\text { Case } 2 \\
\end{array}$} & \multicolumn{2}{|c|}{$\begin{array}{l}\text { Case } 2 \\
\text { Lower }\end{array}$} & \multicolumn{2}{|c|}{$\begin{array}{l}\text { Case 2 } \\
\text { Best Fit }\end{array}$} & \multicolumn{2}{|c|}{$\begin{array}{l}\text { Case } 2 \\
\text { Upper }\end{array}$} \\
\hline & $b_{1}$ & $b_{2}$ & $b_{1}$ & $b_{2}$ & $b_{1}$ & $b_{2}$ \\
\hline Trial 1 & 0.24 & 0.93 & 0.80 & 1.27 & 1.36 & 1.64 \\
\hline Trial 2 & -0.08 & 0.81 & 0.50 & 1.26 & 1.08 & 1.71 \\
\hline Trial 3 & -0.48 & 1.14 & 0 & 1.46 & 0.48 & 1.78 \\
\hline Trial 4 & -0.15 & 1.05 & 0.38 & 1.45 & 0.92 & 1.84 \\
\hline & \multicolumn{3}{|c|}{$\frac{y_{s}}{y_{1}}=K_{1} K_{2} K_{3} K_{4}$} & \multicolumn{2}{|c|}{$\mathrm{Fr}^{0}+0.28$} & \\
\hline & \multicolumn{3}{|c|}{$\frac{y_{s}}{y_{1}}=K_{1} K_{2} K_{3} K_{4}$} & & +0.28 & \\
\hline
\end{tabular}

Figure 2 presents residuals from both the original HEC-18 model and the final modified version. These residuals show some records were better predicted with the original HEC-18 model, but other records show the modified version improves the fit. Overall, the family of equations better predicts the observed field-scale scour measurements based on mean-square error shown in Table 3.

The results of the Case 1 analysis shows that the modified HEC-18 equation with the multiplicative adjustment under predicted relative scour depths in 11 instances, compared to the original equation (Table 4). The modified equation with the additive adjustment over predicts scour in the same number of instances as the original HEC-18 model (Table 4). Similarly, the application of 

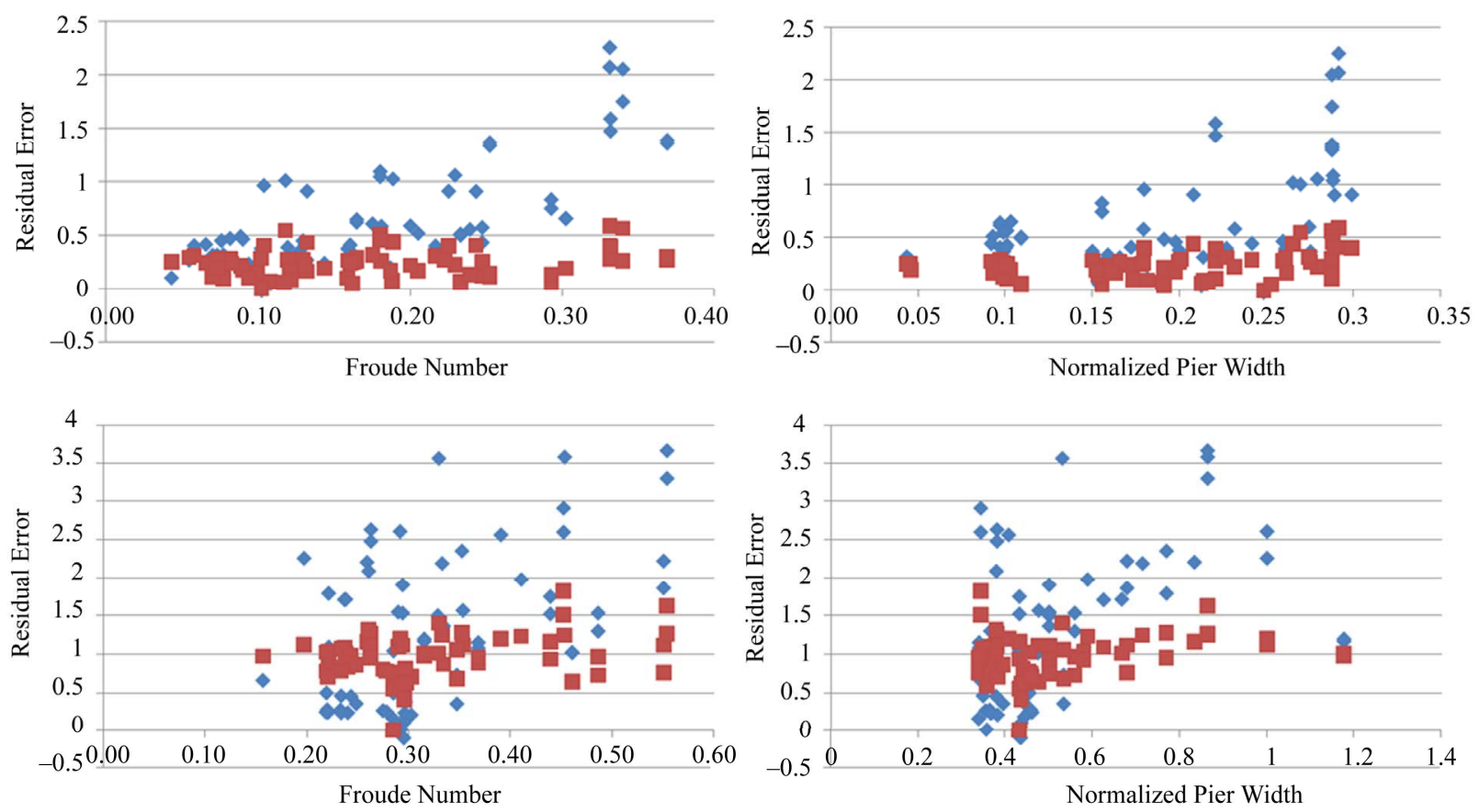

$\diamond$ Original HEC-18 Equation $\square$ Modified HEC-18

Figure 2. Residual comparisons for the final version of the modified HEC-18 family of equations Case 1 (top) and Case 2 (bottom).

the modified model with the multiplicative adjustment results in five more occurrences of under predicted scour when compared to the original HEC-18 model (Table 4). Whereas the modified model with the additive adjustment under predicted scour once (in trial two) when compared to the original model, it over predicted scour once (in trial three) compared to the original model (Table 4). This regression type and model form was chosen for use in the final model due to a significant decrease in meansquare error (Table 2) and the number of over predictions (Table 4).

\section{Discussion and Conclusions}

Pier scour is a complex phenomenon and is difficult to predict. While many improvements have been made in the field over the last 20 years, this complex behavior prevents the use of a single design relationship or method [11]. Like the current array of scour equations, this one is not without its share of difficulties, some of which are discussed below. The equations developed in this work are far from comprehensive; they are merely part of a larger framework of undeveloped equations.

Physically, pier scour depends on various factors including pier geometry, flow depth, approach velocity and bed material characteristics [2]. Many empirical equations exist to predict scour, and compared to physical or numerical models, offer expedience of bridge design. In an attempt to simplify a complex physical system into predictive empirical equations, some empirical models exclude variables. The Mississippi scour equation, which is functionally dependent on pier width and flow depth only, was ranked in the top six performers in a study by Mueller and Wagner [2]. Equation (4a) is independent of approach velocity. However, as seen with the Mississippi equation, an empirical model need not contain every parameter associated with pier scour to perform well [11]. Ettema et al. [11] echo a similar sentiment and state velocity is not a primary parameter to determine maximum scour depth.

Another anomaly is the discontinuity that occurs in scour prediction between use of Equations (9.4a) and (9.4b) as is evidenced by the considerable change in regression parameters and the additive adjustment. This discontinuity is a product of the statistical formulation of the equations, and engineering judgment is required for cases near the transition point $(\mathrm{NPW}=0.30)$. As additional field data becomes available, the regression processes may lead to a smoother and more continuous function.

The Froehlich equation helps address two potential concerns with the proposed equation: the additive adjustment and its reliance on field data. Use of the additive adjustment term in the equation results in a "pseudoscour" even in the case of no flow $(F r=0)$. While this is not physically possible, it is not unique from other exist- 
ing design equations. Specifically, the Froehlich Design equation is both based on field data and uses an additive adjustment. It is also considered among the top performers in the Mueller and Wagner [2] study. Additionally, laboratory-based equations are not without problems (idealized conditions and scale effects). In fact, deficiencies in the leading equations stem from their reliance on laboratory data [11].

This analysis shows that developing a family of equations in a similar format to the current HEC-18 equation (Equation (1)) reduces the mean square error of prediction and reduces the overall amount of over-prediction. This study and others show the current HEC-18 equation significantly over predicts scour in most cases, resulting in increased construction costs. As shown in this study, using field-scale data, partitioning the data set and defining regression parameters for specific conditions leads to significant reductions in estimated scour depths while maintaining scour over prediction.

HEC-18 was chosen for the starting point for this model development because it is the current scour model approved by the FHWA and therefore widely used. Many additions were made to the field of pier scour prediction since the FHWA implemented HEC-18. The FHWA is in the process of evaluating these new models. While the CSU-based equation may not always be the recommended pier scour equation in HEC-18, the authors feel the framework developed in this study can be applied to wide array of base equations and datasets.

\section{Acknowledgements}

The authors would like to acknowledge the Michigan Department of Transportation for support of Project \#108493-Contract 2007-0436 and Project \#85106-Contract 2006-0413. The authors also recognize the comments of all reviewers including the MDOT Bridge Scour Technical Advisory Group and Dr. Peggy Johnson.

\section{REFERENCES}

[1] H. Nassif, A. O. Ertekin and J. Davis, "Evaluation of Bridge Scour Monitoring Methods, F," United States
Department of Transportation, Federal Highway Administration, Trenton, 2002.

[2] D. Mueller and C. R. Wagner, "Field Observations and Evaluations of Streambed Scour at Bridges," United States Department of Transportation, Federal Highway Administration, Mclean, 2005.

[3] G. R. Hopkins and R. W. Vance, "Scour around Bridge Piers," Washington, 1980.

[4] R. Ettema, B. W. Melville and B. Barkdoll, "Scale Effect in Pier-Scour Experiments," Journal of Hydraulic Engineering, Vol. 124, No. 6, 1998, pp. 639-642. doi:10.1061/(ASCE)0733-9429(1998)124:6(639)

[5] P. Johnson, "Comparison of Pier-Scour Equations Using Field Data," Journal of Hydraulic Engineering, Vol. 121, No. 8, 1995, pp. 626-629. doi:10.1061/(ASCE)0733-9429(1995)121:8(626)

[6] E. V. Richardson and S. R. Davis, "Evaluating Scour at Bridges," 4th Edition, United States Department of Transportation, Federal Highway Administration, Washington, 2001.

[7] P. F. Lagasse, J. D. Schall and E. V. Richardson, "Stream Stability at Highway Structures HEC-20," FHWA, 2001, p. 260.

[8] P. F. Lagasse, et al., "Comprehensive Bridge Scour Evaluation Methodology," 5th International Bridge Engineering Conference, Bridges, Other Structures, and Hydraulics and Hydrology, Transportation Research Board Natl Research Council, Washington, Vol. 1-2, 2000, pp. A204-A208.

[9] G. Brunner, "River Analysis System Hydraulic Reference Manual," D.o. Defense, Davis, 2008.

[10] M. Landers, D. Mueller and G. Martin, "Bridge-Scour Data Managment System User's Manual," United States Geologic Survey, Reston, 1996.

[11] R. Ettema, G. Constantinescu and B. Melville, "Evaluation of Bridge Scour Research: Pier Scour Processes and Predictions," N.C.H.R. Program, 2011.

[12] D. Froehlich, "Analysis of Onsite Measurements of Scour at Piers," National Hydraulic Engineering Conference, New York, 1988. 